\title{
Other Specified Parts of Pancreas
}

National Cancer Institute

\section{Source}

National Cancer Institute. Other Specified Parts of Pancreas. NCI Thesaurus. Code C12273.

Any component associated with the pancreas that is different from the one(s) previously specified or mentioned. 